\title{
Compositional and Structural Versatility in an Unusual Family of Anti-Perovskite Fluorides: $\left[\mathrm{Cu}\left(\mathrm{H}_{2} \mathrm{O}\right)_{4}\right]_{3}\left[\left(M \mathrm{~F}_{6}\right)\left(M^{\prime} \mathrm{F}_{6}\right)\right]$
}

\author{
Justin B. Felder, Jeongho Yeon, Mark D. Smith, Hans-Conrad zur Loye* \\ *Department of Chemistry and Biochemistry, University of South Carolina, Columbia \\ South Carolina, 29208, USA
}




\section{Supplemental Information}
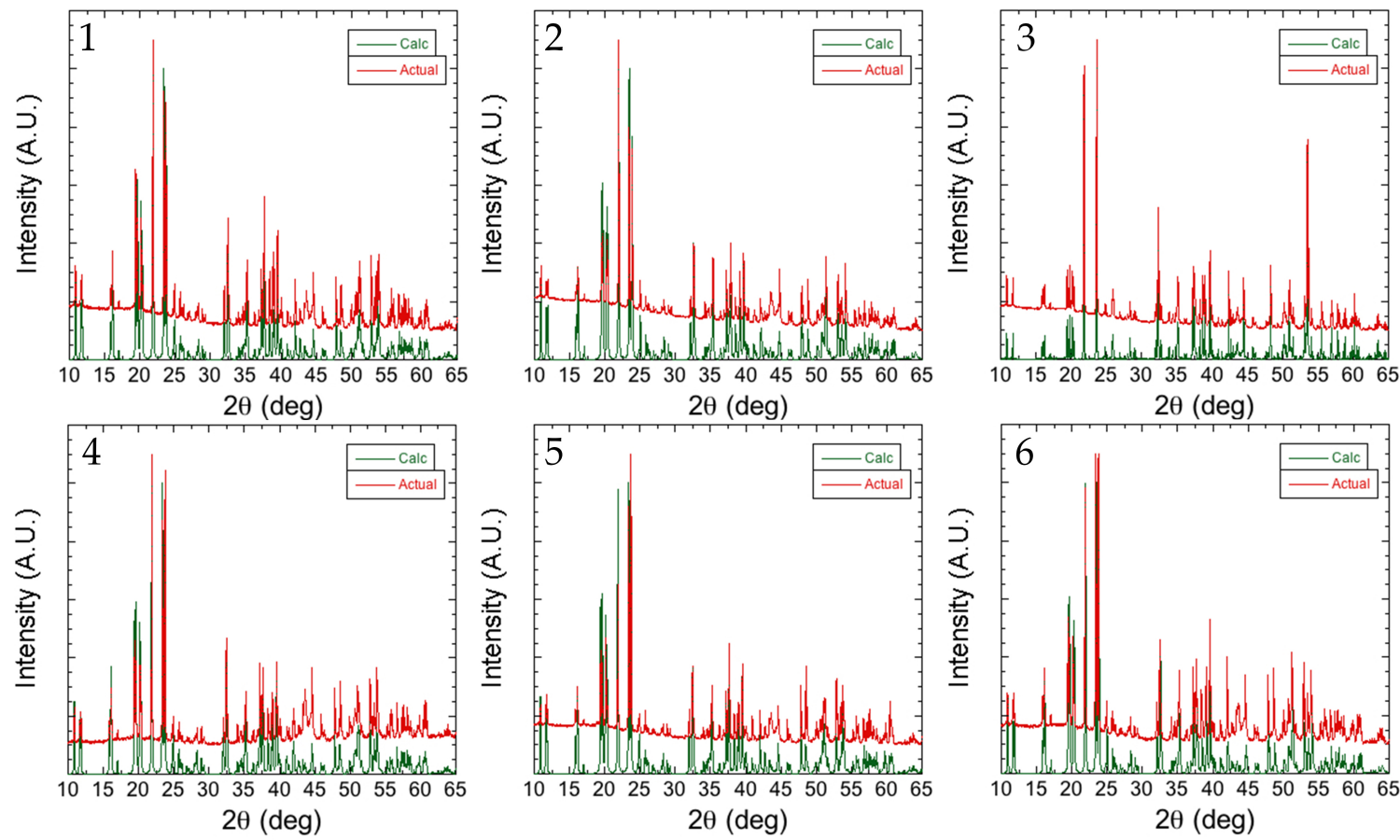

Figure S1: The PXRD data for phases 1-6. Calculated data from the .CIF is shown in green, and actual data is shown in red. 

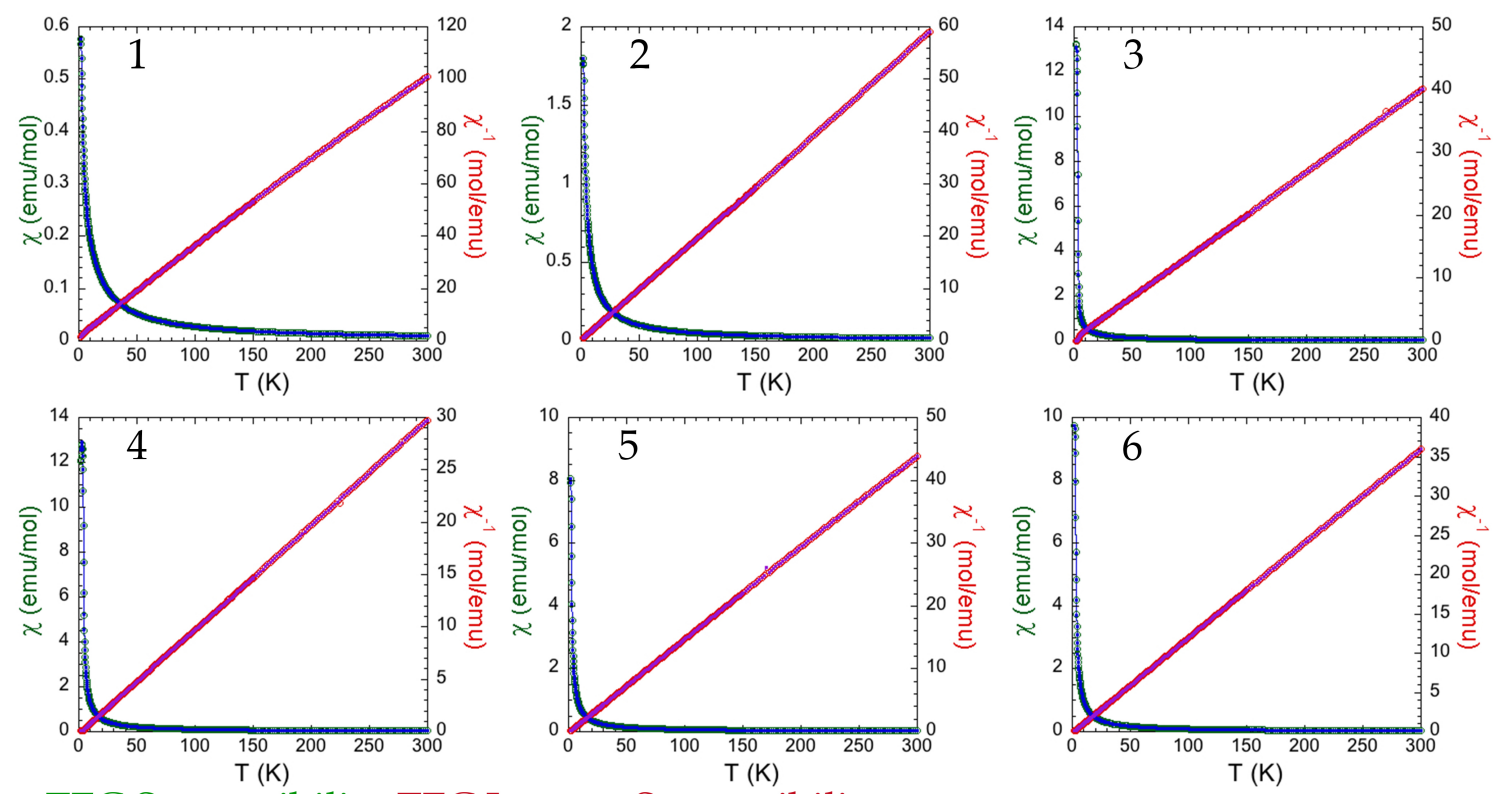

ZFC Susceptibility ZFC Inverse Susceptibility

\section{FC Susceptibility FC Inverse Susceptibility}

Figure S2: The magnetic susceptibility and inverse magnetic susceptibility of materials 1-6. Both the field cooled and zero-field cooled data is shown, and overlay perfectly for all materials except $\mathbf{3}$, which shows slight field dependence at $2 \mathrm{~K}$.
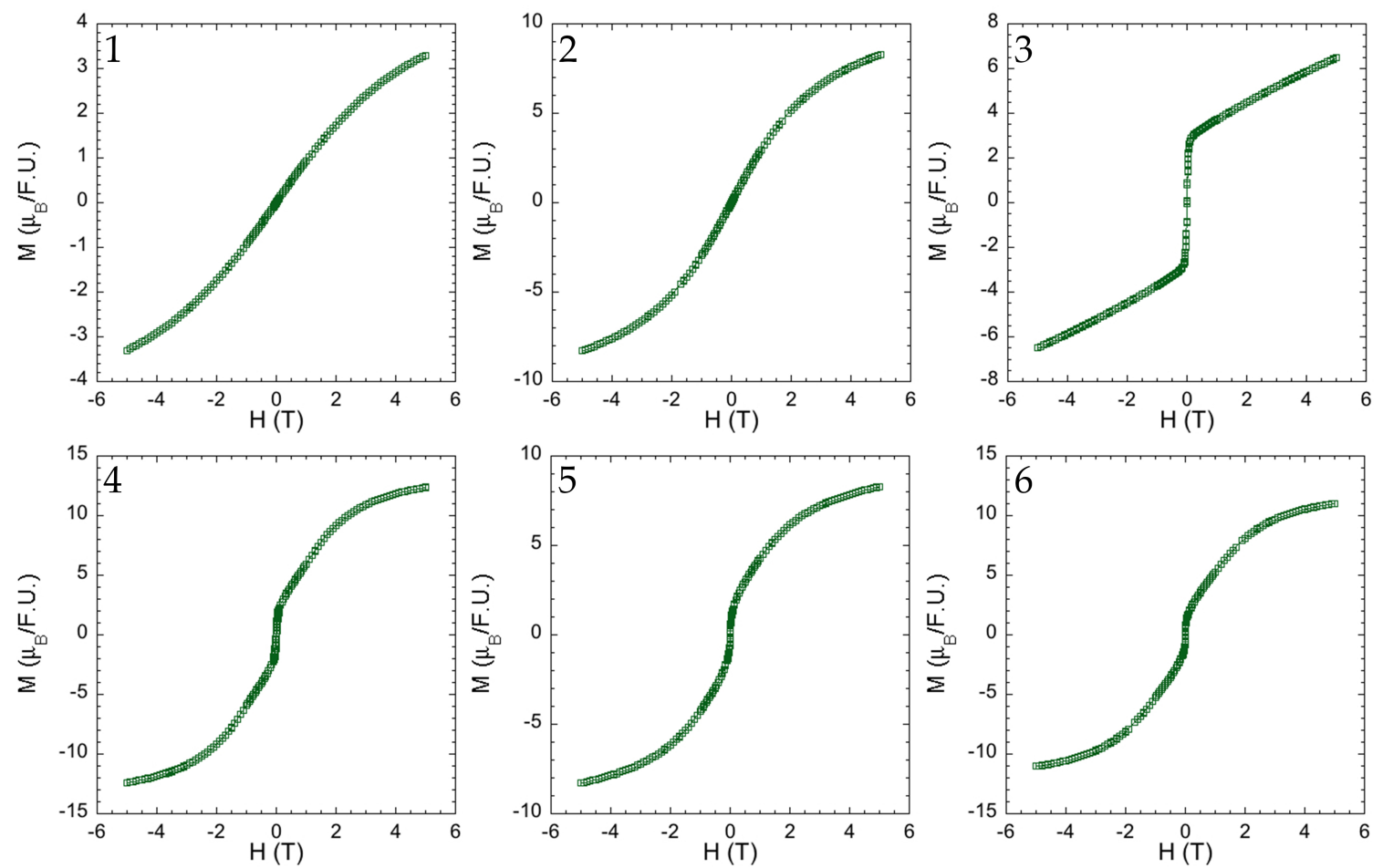

Figure S3: The magnetization plots for materials 1-6. Five quadrant measurements were performed at $2 \mathrm{~K}$ for all reported compounds. 
